\title{
Grape, Wolfgang, Unerwartetes und Unterhaltsames in der Kunst des frühen und hohen Mittelalters
}

\section{Thomas Lienhard}

\section{OpenEdition}

\section{Journals}

Édition électronique

URL : http://journals.openedition.org/ifha/2160

DOI : 10.4000/ifha. 2160

ISSN : 2198-8943

Éditeur

IFRA - Institut franco-allemand (sciences historiques et sociales)

Référence électronique

Thomas Lienhard, « Grape, Wolfgang, Unerwartetes und Unterhaltsames in der Kunst des frühen und hohen Mittelalters », Revue de l'IFHA [En ligne], Date de recension, mis en ligne le 01 janvier 2010 consulté le 22 septembre 2020. URL : http://journals.openedition.org/ifha/2160 ; DOI : https://doi.org/ $10.4000 /$ ifha. 2160

Ce document a été généré automatiquement le 22 septembre 2020.

(C)IFHA 


\title{
Grape, Wolfgang, Unerwartetes und Unterhaltsames in der Kunst des frühen und hohen Mittelalters
}

\author{
Thomas Lienhard
}

1 C'est à un ouvrage déroutant que l'on a affaire ici. Il l'est d'abord parce qu'en l'absence totale d'introduction, ce n'est qu'au fil de la lecture que l'on comprend progressivement l'enjeu même de la démonstration. Vers le milieu du livre, on perçoit ainsi qu'il s'agit de prouver que l'art figuré du second Moyen Âge (essentiellement l'iconographie livresque et la peinture murale) aurait évolué vers un sens accru de l'humour, du profane et du quotidien ; cette mue se serait produite principalement à partir du XIIe siècle, en opposition avec les normes morales et artistiques imposées par l'Église durant la période précédente. Cette fin du Moyen Âge aurait ainsi développé une sensibilité très proche de la nôtre, ce qui devrait nous dissuader, selon l'auteur, d'envisager cette époque " comme plus moyenâgeuse qu'elle ne le fut réellement » (p. 160). Si l'on ne peut que souscrire à ces grandes lignes, la démonstration proposée par W.G. peine pourtant à emporter la conviction du lecteur, et butte sur trois écueils principaux.

2 Avant tout, la présentation du corpus analysé ne répond pas aux critères scientifiques. Pour chacune des œuvres étudiées, l'auteur ne fournit que quelques indications sommaires de localisation ; aucune donnée n'est accordée à propos des dimensions de l'image, ni des éventuelles modifications que celle-ci a pu subir depuis ses origines. Le lecteur en est ainsi réduit à rechercher lui-même des informations supplémentaires pour déterminer si telle illustration, qui peut le surprendre au sein d'un manuscrit déterminé, s'y trouvait dès l'origine ou si, la codicologie faisant foi, elle y a été insérée ultérieurement. Surtout, l'ouvrage prive cruellement le lecteur de contexte. Ainsi, en ce qui concerne les fresques ou la statuaire religieuse, il est généralement impossible, à la lecture de ce seul livre, de déterminer où se trouvait l'objet au sein du bâtiment (on sait pourtant que dans un bâtiment ecclésiastique, le sud appelait souvent un programme bien différent de l'est), avec quel angle de vue le spectateur pouvait l'appréhender, etc. 
De même, dans le cas des manuscrits, il serait parfois crucial de connaître non seulement les données textuelles qui suivent telle ou telle enluminure (ce que l'auteur indique parfois), mais également celles qui la précèdent.

Cette présentation incomplète ne facilite pas la tâche au lecteur ; mais elle induit parfois en erreur l'auteur lui-même, qui court d'autant plus ce risque qu'il semble parfois gêné par une connaissance approximative du champ religieux médiéval. C'est ainsi, par exemple, qu'il dérape sur la représentation d'un cheval courant au milieu de l'eau, qu'il interprète comme un monstre marin issu du panthéon païen scandinave ( $\mathrm{p}$. 34 et suiv.) : un bref coup d'œil sur le texte qui précède cette illustration l'aurait aisément convaincu qu'il s'agit en réalité de la traversée de la mer Rouge par les Hébreux. De même, l'auteur s'en prend à un manuscrit dans lequel une illustration représente, en-dessous d'une Crucifixion, Jésus sur un navire en compagnie de douze personnes. Pour W.G., c'est d'un bateau des morts qu'il s'agit, sur le modèle de la barque de Charon, et donc d'une survivance du paganisme antique (p. 22) ; il semble pourtant bien plus simple et plus classique de voir là une représentation du Christ et de ses disciples dans la tempête, scène fondatrice pour l'Église et qui fait tout son sens à côté de la Crucifixion. Dans le souci manifesté par l'auteur de prendre l'historiographie à contre-pied, la témérité l'emporte ainsi parfois sur le courage.

4 L'ouvrage pèche enfin par l'imprécision de ses concepts, en particulier lorsqu'il s'efforce de traquer les traces de paganisme ou d'anticléricalisme au Moyen Âge. Certes, on peut légitimement opposer, comme le fait l'auteur, l'iconophobie des premiers cisterciens et la représentation raffinée de femmes nues au XVe siècle. Mais faut-il pour autant considérer (p. 12) que la figure d'un dragon au sein d'une église implique une concession aux puissances préchrétiennes, alors que ledit dragon est visiblement asservi en position de porte-chandelles ? Que la présence d'aliments familiers (des Knödel et des saucisses) sur une Nativité constitue une " profanation » (p. 87) ? On ne rappellera jamais assez que le domaine du païen n'est pas identique à celui du profane, et que ce dernier ne constitue pas une agression frontale contre les normes ecclésiastiques, fussent-elles altimédiévales. Il est vrai que pour l'emploi de ces concepts, W.G. est assurément gêné par la bibliographie incomplète à laquelle il recourt : $90 \%$ des titres cités ont plus de vingt ans, et seuls $10 \%$ sont publiés dans d'autres langues que l'allemand, ce qui ne plaide pas pour une historiographie récente ni internationale. En particulier, on est frappé par l'absence de noms incontournables sur le sujet des croyances médiévales, tels que celui de Peter Brown, Ian Wood, Yitzhak Hen ou Bruno Dumézil. On l'aura compris : l'ouvrage que l'on recense ici ne présente pas le dernier état de la recherche.

5 Il est vrai que, même si l'iconographie médiévale du profane n'a pas la portée polémique, voire révolutionnaire, que lui prête W.G., il est pourtant légitime d'analyser son évolution au cours de l'histoire européenne. Or en ce domaine, l'ouvrage rend des services, traquant ainsi les premiers cas de représentations du travail manuel ; les premières fresques ou enluminures qui représentent un paysage local de manière réaliste, et non pas seulement idéelle ; les premières apparitions, dans l'iconographie médiévale, de la gastronomie locale (en l'occurrence les saucisses tyroliennes déjà citées) ; les premiers signes d'intérêt pour le corps féminin, qui vont jusqu'à la représentation flatteuse de femmes au bain au XIVe siècle; les premiers développements, enfin, de fables animales parfois en plein cœur des églises. L'auteur accentue parfois exagérément les ruptures chronologiques (bien des traits qu'il 
caractérise comme des nouveautés du XIIe siècle sont déjà présents, en réalité, à l'époque carolingienne), mais il rassemble incontestablement des jalons précieux pour celui qui veut reconstituer les grandes évolutions en ce domaine.

6 Au final, le lecteur de ce livre est confronté à un corpus intéressant, mais l'analyse qui en est faite est souvent lacunaire. Ce qui reste donc unerwartet après cette lecture, c'est que le Deutscher Kunstverlag ait consenti à l'éditer.

7 Thomas Lienhard (IFHA) 